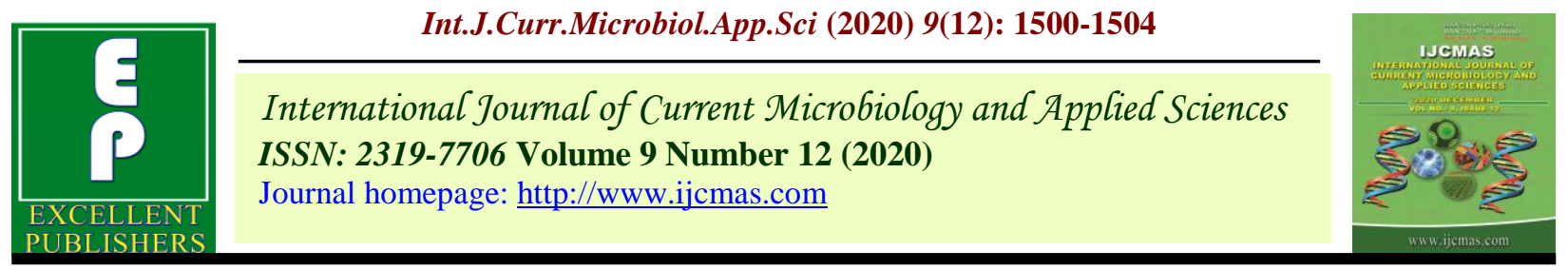

Original Research Article

https://doi.org/10.20546/ijcmas.2020.912.178

\title{
Impact of Direct Seeded Rice on Farm Profitability and Technical Efficiency: An Evidence from Karnataka
}

\author{
N. Mallikarjuna Swamy* \\ Department of Agricultural Economics, UAS, Bangalore, India \\ *Corresponding author
}

\section{A B S T R A C T}

\section{Keyw ords \\ Direct seeded rice, \\ Water, Labour, \\ Canal command \\ Article Info \\ Accepted: \\ 12 November 2020 \\ Available Online: \\ 10 December 2020}

The Direct seeded rice (DSR) have potential role in addressing the issues related to water and labour scarcity coupled with Greenhouse gases (GHGs) emission. The result of the present study indicates that DSR cost of production of which lower by 12 percent with $5 \%$ significance level. The returns per rupee of expenditure was found to be higher as against of transplanted rice. The farmers who are practising DSR have higher technical efficiency than Transplanted Rice (TPR) growing farmers. About $35 \%$ of the farmers come in the range $70-90$ Technical Efficiency (TE) in DSR as against of nearly $12 \%$ in transplanted rice. This acknowledges the significance in augmenting the rice production without productivity loss. The awareness campaign and training to farmers about DSR particularly in command area to augment the rice production in Karnataka.

\section{Introduction}

The Agricultural sector has the moral responsibility in food and nutritional security and in consonance with preserving the ecosystem. India achieved self-sufficiency in rice production. In fact, rice production is reached about 201 million tons in 2020 since it is an important staple food crop of about $70 \%$ of the population. However, consumption of rice increased greater phase than that of production in the last decade. It was mainly due to decline in the productivity level. The Food and Agricultural Organisation (FAO) estimate suggest the rice production would be augmented through improvement in productivity level amidst deteriorating water table and vagaries of monsoon and in coupled with labour scarcity.

In fact, India is the largest exploiter of groundwater in the world due to widespread cultivation of transplanted rice without proper irrigation management. For instance, Punjab has highest land productivity but lower water productivity because of inefficient irrigation management. Besides, the study published in the National Academy of Sciences of the United States of America indicates that nitrous oxide emissions from Transplanted rice (TPR) contribute of about $99 \%$ of the total climate impact which contributed substantially to global warming pollution. This puts greater thrust on feeding the 
population with limited water resources in sustainable manner has become the dire need. The previous studies reported that proper management practices (irrigation, chemical fertilizers) in combating the green house gas.

The direct seeded method has the potential in reducing the water requirement and nutrients as compared to transplanted rice. Under this system, sowing of rice seeds directly in the soil rather than transplanting which prevents soil degradations and hard pan formation. It enables in crop matures 10-15 days earlier without compromising yield level. There is paucity of literature with regard to comparative economics and resource use efficiency in this regard. Therefore, this study focuses on relative economic advantage of DSR over TPR with regard to farm profitability and technical efficiency in Karnataka.

\section{Materials and Methods}

\section{Sampling technique}

The multiple stage random sampling procedure was employed to collect relevant information on the identified variables from the Tungabhadra Command area of Karnataka during the 2017-18 using the pre-tested questionnaire. In the first stage, two talukas were selected from Bellary districts Siruguppa and Bellary. Second stage cluster of 5 to 6 villages from each taluk were selected randomly. In the third stage 110 sampled farmers from each method of cultivation (DSR and TPR rice) thus, totally 220 paddy cultivators, comprising of 110 DSR and 110 TPR in command area.

\section{Empirical tools}

Cost concepts analysis: Employed to estimate the comparative economics of DSR and TPR in Karnataka.

\section{Stochastic Frontier Approach}

Stochastic Frontier Analysis (SFA) was employed for estimating the Technical Efficiency (TE) for DSR and TPR. This parametric method of SFA takes care of random shocks, while non-parametric data envelopment analysis assumes the deterministic frontier. The frontier production implies potential output could be produced with given resources and technology. The SFA function can be specified as:

$\mathrm{Q}_{\mathrm{i}}=\mathrm{f}\left(\mathrm{X}_{\mathrm{i}} ; \beta\right) \exp \left(-\mathrm{u}_{\mathrm{i}}\right)$ and $0 \leq \mathrm{u}_{\mathrm{i}}<\infty ; \mathrm{i}=1$, $2, \ldots, n(1)$

Where, $Q_{i}$ represents the DSR and TPR yield for the $i^{\text {th }}$ sample unit; $X_{i}$ is a vector of inputs and $\beta$ is a vector of parameters. If production unit is efficient, its output is equal to potential output indicating farmers adopting the good agricultural practices. Therefore, TE is the ratio of the actual output $\mathrm{Q}_{\mathrm{i}}$ and potential output $f($.) given the level of input use and the technology (Aigner et al., 1977; Tavva,S, 2017).

Using the above equation (1), we can write this measure as:

$\mathrm{TE}=\mathrm{Q}_{\mathrm{i}} / \mathrm{f}\left(\mathrm{X}_{\mathrm{i}} ; \beta\right)=\exp \left(-\mathrm{u}_{\mathrm{i}}\right) \ldots(2)$

Note that $u_{i}$ is zero if the production unit produces the potential output and is less than zero when production is below the frontier.

\section{Results and Discussion}

The relative cost analysis between DSR and TPR helps to know the percent of difference in respective cost components.

\section{Comparative economics of DSR and TPR rice}

The comparative cost of DSR over TPR in Karnataka has been depicted in the table 1 the different cost components are categories into 
Land preparation, labour, seed, fertilizer and irrigation cost. The cost of seeds of DSR was Rs. 4,950 as against of Rs 2,500 with 98 per cent difference in the cost. This significant difference in the seed cost between the DSR and TPR was at 1 per cent level of significance. The TPR requires higher dose of fertilisers as compared to direct seeded rice. The amount spent for TPR was Rs. 4589 which is higher than that (Rs. 3256) for DSR rice which was about $29 \%$ higher. There is significant difference between the DSR and TPR at $5 \%$ significance.

Table.1 The comparative cost of DSR and TPR rice in Karnataka (Rs/acre)

\begin{tabular}{|l|l|l|l|l|}
\hline \multicolumn{1}{|c|}{ Particulars } & \multicolumn{1}{c|}{ TPR } & \multicolumn{1}{c|}{ t value } & \% of difference \\
\hline Land preparation & 6520 & 9650 & 0.78 & -32.44 \\
\hline Labour cost & 6540 & 4123 & 0.23 & 58.62 \\
\hline Seed cost & 4950 & 2500 & $3.56^{* *}$ & 98.00 \\
\hline Fertilizer cost & 3256 & 4589 & $2.56^{* *}$ & -29.05 \\
\hline Irrigation cost & 540 & 5236 & $2.15^{* *}$ & -89.69 \\
\hline Total variable cost & 21806 & 26098 & 0.35 & -16.45 \\
\hline Total Fixed cost & 1254 & 1325 & 0.78 & -5.36 \\
\hline Marketing cost & 3850 & 5200 & 1.23 & -25.96 \\
\hline Total cost & 26910 & 32623 & 1.98 & -17.51 \\
\hline
\end{tabular}

DSR: Direct seeded rice; TPR: Transplanted rice

Table.2 The profitability of DSR over TPR in Karnataka

\begin{tabular}{|c|c|c|c|c|}
\hline Particulars & DSR(DSR) & TPR(TPR) & $\begin{array}{c}\text { T- } \\
\text { value }\end{array}$ & $\%$ of difference \\
\hline Cost of production (Rs/Q) & 861.12 & 981.14 & 1.56 & -12.23 \\
\hline Yield (Q/ha) & 31.25 & 33.25 & $2.12 * *$ & -6.02 \\
\hline Gross return (in Rs) & 45312.50 & 48212.50 & 1.56 & -6.02 \\
\hline Net returns (in Rs) & 18402.50 & 15589.50 & $2.45 * *$ & 18.04 \\
\hline $\begin{array}{l}\text { Net returns per rupee of } \\
\text { investment }\end{array}$ & 1.68 & 1.48 & $2.17 * *$ & 13.94 \\
\hline
\end{tabular}

DSR: Direct seeded rice; TPR: Transplanted rice

Table.3 Percentage and frequency of farmers based on the technical efficiency in both DSR and TPR rice

\begin{tabular}{|c|c|c|c|c|}
\hline Technical efficiency & \multicolumn{2}{|c|}{ DSR } & \multicolumn{2}{c|}{ TPR } \\
\hline & Frequency & \% of total & Frequency & \% of Total \\
\hline $\mathbf{4 4 0}$ & 23 & 20.91 & 28 & 25.45 \\
\hline $\mathbf{4 1 - 5 0}$ & 18 & 16.36 & 32 & 29.09 \\
\hline $\mathbf{5 1 - 6 0}$ & 21 & 19.09 & 22 & 20.00 \\
\hline $\mathbf{6 1 - 7 0}$ & 8 & 7.27 & 14 & 12.73 \\
\hline $\mathbf{7 1 - 8 0}$ & 15 & 13.64 & 12 & 10.91 \\
\hline $\mathbf{8 1 - 9 0}$ & 23 & 20.91 & 2 & 1.82 \\
\hline$>\mathbf{9 0}$ & 2 & 1.82 & 0 & 0.00 \\
\hline Mean & 0.87 & & 0.74 & \\
\hline
\end{tabular}


Fig.1 The percentage of farmers based on technical efficiency

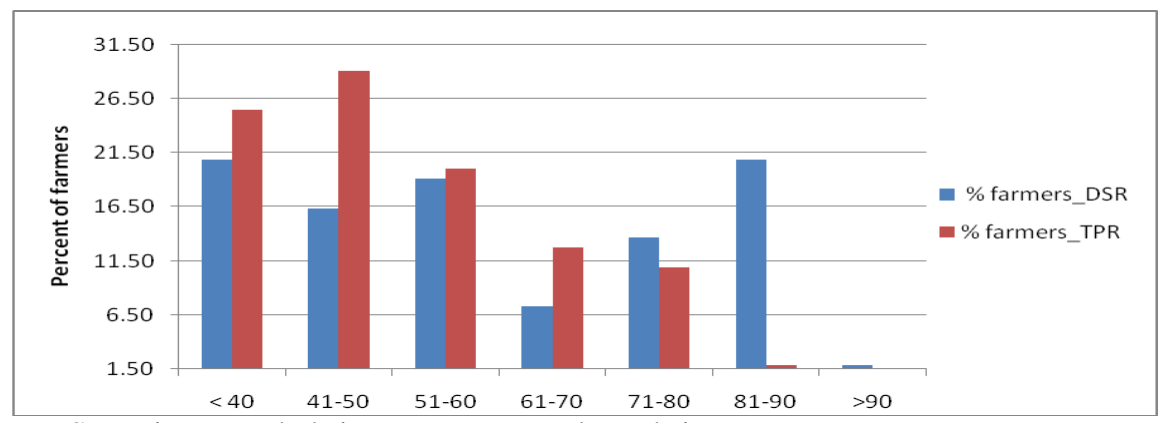

DSR: Direct seeded rice; TPR: Transplanted rice

Fig.2 The relationship between TE and productivity (DSR and TPR)

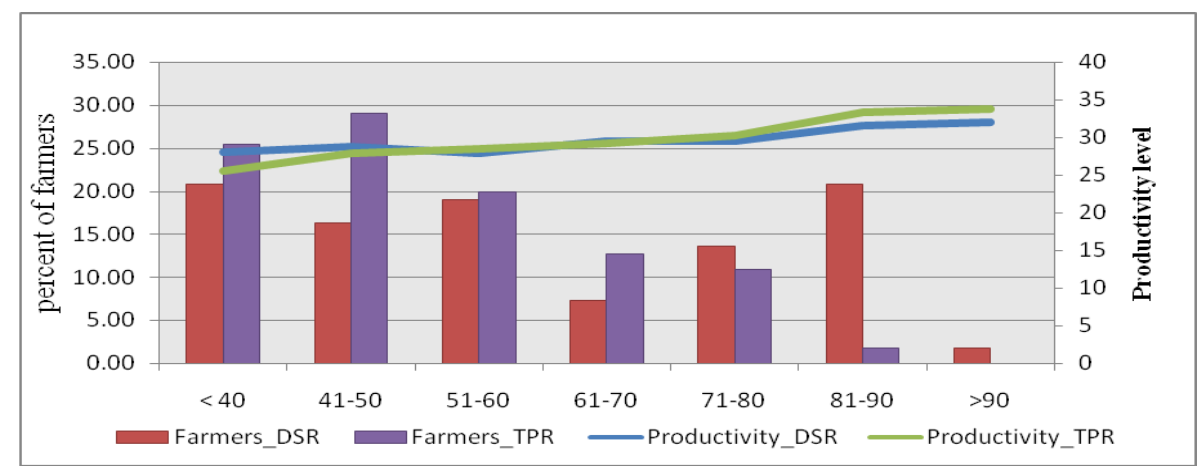

DSR: Direct seeded rice; TPR: Transplanted rice

This is obvious because TPR requires higher dosage of nitrogen fertilizer due to leaching out effect in field. With respect to irrigation cost, the farmers spent for TPR was Rs.5,236 which is higher than that of Rs.540 for DSR with respect to irrigation cost which is about $89 \%$ higher and also significant at $5 \%$ level of significance. This is because number of irrigation (10) for TPR as against of only 2 in DSR. There is significant difference in the number of irrigation between the DSR and TRP at $5 \%$ LoS. The total cost of DSR was Rs.26,910 as compared to Rs.32,623 with -17 per cent difference in the cost, however nonsignificant.

The comparative profitability of DSR over the TPR in Karnataka is depicted in the Table 2. The results implies that cost of production of DSRRs/q 861.12as against of Rs /q 981.14 which is about lower by 12.23 percent however non- significant. There is significant yield difference between the DSR and TPR with difference of -6 percent. Noteworthy returns per rupee of investment found to be higher in case of DSR than TPR with significant difference of $13.94 \%$ at 5 level of significance. This acknowledges the DSR have comparative advantage in fostering the farm profitability.

\section{Technical efficiency of DSR and TPR farmers}

The distribution of farmers between the DSR and TPR rice based on technical efficiency is indicated in Table 3 and fig. 1. The results implies $23 \%$ of DSR growing farmers as against of $25 \%$ farmers in TPR growing farmers falls under the $<40$ Technical Efficiency (TE). About 21 per cent of the DSR growing farmers whilst only $1.8 \%$ of TPR growing farmers lie in the 81-90 TE. The mean technical efficiency level DSR and TPR growing farmers was 0.87 and 0.74 
respectively. The mean technical efficiency of the DSR growing farmers was slightly higher due to efficient utilization of resources compared to TPR rice growing farmers. The DSR and TPR rice production could be augmented by $13 \%$ and $26 \%$ with use of same inputs and technology at farm level. The results are consonance with Goyal et al., 2006 for rice farmers of Haryana.

\section{Relationship between the TE and productivity of TPR and DSR}

The relationship between TE and productivity level between the DSR and TPR growing farmers has been depicted fig. 2. The results imply that there positive relationship between TE and productivity level between the DSR and TPR with correction coefficient of 0.56 at $5 \%$ LoS. The productivity was about $28 \mathrm{q} / \mathrm{ha}$ for DSR as against of $25.56 \mathrm{q} / \mathrm{ha}$ for TPR with less than $40 \%$ of TE whilst $29.50 \mathrm{q} / \mathrm{ha}$ and 29.25 $\mathrm{q} /$ ha of productivity level with range of 61 to 70 $\%$ of TE. This clearly indicates that as TE increases in consonance with increase in the productivity level in both cases.

In conclusion, India achieved self-sufficiency in rice production with 201 million tons during 2019-20 with $70 \%$ population staple food in India. However, consumption of rice increased greater phase than that of its production in the last decade. The augmentation of rice production could be possible through improvement in the productivity level amidst growing menace of depletion of groundwater and labour scarcity. However, in India about 60 $\%$ of rice cultivation is by flooded or transplanted method further aggravates towards the prevailing problems. Thus, the DSR have potential role in addressing the issues related to water and labour scarcity.
The results of the present study indicates cost of production of DSR as comparative to TPR which lower by 12 percent and significant at 5 $\%$ and noteworthy returns per rupee of investment found to be higher in case of DSR than TPR with significant difference of $13.94 \%$ at 5 level of significance. Further, the mean technical efficiency of the DSR growing farmers was slightly higher due to efficient utilization of the resources compared to TPR rice growing farmers. This acknowledges the significance in augmenting the rice production without productivity loss. The farmers are needs to be educated and create awareness about the DSR particularly in the command area through awareness campaign and training to the farmers.

\section{References}

Food and Agricultural Organisation http://www.fao.org/economic/est/publications/ri ce-publications/rice-market-monitor$\mathrm{rmm} / \mathrm{en} /, 2020$.

Goyal, S.K. Suhag, K. S. and Pandey, U.K. 2006. An Estimation of Technical Efficiency of Paddy Farmers in Haryana State of India. Indian Journal of Agricultural Economics. 61(1): 245254.

Aigner, D. Lovell, C. A. K. and Schmidt, P. 1977. Formulation and Estimation of Stochastic Frontier Production Function Models. Journal of Econometrics. (6): 21-37.

Tavva, S. Aden Aw-Hassan and Javed Rizvi. 2017. Technical efficiency of wheat farmers and options for minimizing yield gaps in Afghanistan. Outlook agriculture, 46(1): 13-19.

\section{How to cite this article:}

Mallikarjuna Swamy, N. 2020. Impact of Direct Seeded Rice on Farm Profitability and Technical Efficiency: An Evidence from Karnataka. Int.J.Curr.Microbiol.App.Sci. 9(12): 1500-1504. doi: https://doi.org/10.20546/ijcmas.2020.912.178 